\title{
Pandemic (H1N1) 2009 influenza
}

\section{Ben Polkinghorne ${ }^{\mathrm{A}}$, Kate Ward $^{\mathrm{B}}$ and Richard Totaro ${ }^{\mathrm{C}}$}

ANSW Public Health Officer Training Program, NSW Department of Health

${ }^{\mathrm{B} C o m m u n i c a b l e ~ D i s e a s e s}$ Branch, NSW Department of Health

${ }^{\mathrm{C}}$ Intensive Care Service, Royal Prince Alfred Hospital

On 11 June 2009, the World Health Organization declared the first human influenza pandemic since 1968-1969. The responsible virus, pandemic (H1N1) 2009 influenza, is a novel triple-reassortant influenza A virus, incorporating avian, swine and human influenza genes. ${ }^{1}$ The virus is resistant to the anti-influenza medications, amantadine and rimantadine, but is generally sensitive to the neuraminidase inhibitors, oseltamivir and zanamivir.

Pandemic (H1N1) 2009 influenza infection has proven to be mild in most cases, severe in some and moderate overall. Symptoms include those typical of influenza (fever, chills, cough, sore throat, fatigue and muscle aches). In some cases, gastrointestinal symptoms (including vomiting and diarrhoea) have been reported.

Some people are at increased risk for severe infection, including those who are pregnant; have chronic lung disease; are obese; have chronic cardiovascular, haemotological, renal or hepatic disease; have neurological or metabolic disorders; are immunosuppressed; or are of Aboriginal or Torres Strait Islander background.

Pandemic (H1N1) 2009 influenza infection peaked in New South Wales (NSW) in mid-July 2009. As of 29 July, there were 3895 laboratory-confirmed cases in NSW, with 21 related deaths. NSW public hospitals reported a total of 846 emergency department admissions and 128 intensive care unit admissions of patients with confirmed H1N1 as of 29 July.

\section{Cruise ships}

Cruise ships presented a unique challenge to NSW Health during the public health response to the pandemic.

The Dawn Princess arrived in Sydney on 23 May with a small number of influenza A-positive passengers. Australia had just entered the CONTAIN pandemic response phase, which mandated strong border measures and tracing of all contacts of confirmed cases. As the ship had visited Hawaii, an area experiencing community transmission of pandemic influenza, all passengers and crew entered quarantine upon disembarking until the results of urgent pandemic influenza tests were available. All results returned a negative result that evening and quarantine measures were lifted.

The Pacific Dawn, however, had not sailed to any areas of concern for pandemic (H1N1) 2009 influenza. Consequently, passengers and crew were allowed to disembark upon arrival in Sydney on 25 May, with two passengers having returned positive influenza $A$ test results presumed seasonal influenza. Specimens from four ill passengers taken onboard the ship were couriered to a laboratory for testing, as was routine for all influenza specimens at that time. The tests of two of these passengers returned positive for pandemic (H1N1) 2009 influenza.

As a result, that evening all disembarked passengers were requested to enter home or hotel isolation/quarantine and to seek medical attention if symptoms developed. A NSW Health public health practitioner accompanied the Pacific Dawn on its next voyage and despite two further staff contracting pandemic (H1N1) 2009 influenza, rapid isolation ensured no passengers from that cruise contracted the disease.

Overall, 84 Pacific Dawn passengers and crew tested positive for pandemic (H1N1) 2009 influenza after the first voyage. However, due to the co-operation of the passengers and crew, and compliance with isolation and quarantine measures, the outbreak was successfully contained.

\section{Extra-corporeal membrane oxygenation}

Veno-venous extra corporeal membrane oxygenation (ECMO) provides support for patients with severe respiratory failure. It involves venous blood from the patient being accessed from a large central vein (usually the femoral vein), passed through an oxygenator, and returned to the central venous system. ${ }^{2}$

Prior to the pandemic, veno-venous ECMO was used rarely for treatment of the complications of influenza. During July 2009, up to 14 people were simultaneously receiving ECMO treatment for severe respiratory failure in NSW intensive care units. The length of ECMO treatment ranged from 1 day to several weeks.

As ECMO machines are located in metropolitan Sydney, transportation of ECMO patients became a critical issue. A new ECMO Medical Retrieval Service had recently been established in response. NSW Ambulance helicopters and ambulances were refitted to transport ECMO patients and medical teams. There are now 43 ECMO 
machines in NSW public hospitals; 25 are designated as cardiac-specific (veno-arterial ECMO) and 18 as venovenous ECMO; however, all 43 can be used for either indication. $^{3}$

\section{References}

1. Morens DM, Taubenberger JK, Fauci AS. The persistent legacy of the 1918 influenza virus. N Engl J Med 2009; 361(3):

225-9. doi:10.1056/NEJMp0904819
2. Marasco SF, Lukas G, McDonald M, McMillan J, Ihle B. Review of ECMO (extra corporeal membrane oxygenation) support in critically ill adult patients. Heart Lung Circ 2008; 17(Suppl 4): S41-7. doi:10.1016/j.hlc.2008.08.009

3. Della Bosca J. New medical retrieval service for critically ill patients 2009. Media Release: NSW Minister for Health; 21 July 2009. Available from: http://www.health.nsw.gov.au/ news/2009/20090721_00.html (Cited 24 September 2009.)

\section{NSW Public Health Bulletin Subscription Form and Electronic Early Alert Service}

To subscribe to the hard copy of the NSW Public Health Bulletin or to change your subscription details please complete this form and return it by email (phbulletin@doh.health.nsw.gov.au) or fax (61 29391 9232).

The Bulletin can be accessed electronically from www.publish.csiro.au/journals/phb. Subscribe to the Early Alert service to be notified as soon as it appears online (www.publish.csiro.au/earlyalert).

\section{Subscription information}

$\square$ I wish to receive the NSW Public Health Bulletin:

My details are as follows

Name:

Organisation:

Mailing Address:

State: Postcode: Country:

Telephone: Facsimile:

Email:

\section{Change of Address}

I wish to change my mailing details, as follows:

Name:

From: [Insert old address]

To: [Insert new address] 